\title{
A tecnologia em sala de aula como ferramenta pedagógica: uma perspectiva pela ótica de alunos de uma instituição de ensino no município de Botucatu (SP)
}

\author{
Technology in the classroom as a pedagogical tool: a perspective by \\ the view of students from an educational institution in Botucatu (SP)
}

Mike Ceriani de Oliveira Gomes Especialista em Metodologia de Ensino da Língua Inglesa pelo Instituto Pedagógico de Minas Gerais (IPEMIG) mikegd1@hotmail.com

\author{
Mariana Wagner de Toledo Piza \\ Universidade do Estado de São Paulo (UNESP) \\ Instituto Toledo de Ensino (ITE) \\ marywagner.adm@gmail.com
}

Resumo: A principal questão abordada neste artigo é a forte adesão às tecnologias em sala de aula, com foco ao estudo de seu bom aproveitamento. Há uma explanação teórica na qual se debate como o mesmo processo já vem ocorrendo no passar dos anos, considerando outras tecnologias senão a dos Smartphones, que estão em ascensão no Brasil e no mundo, estando muito presentes também em sala de aula. Para haver uma discussão de dados, optou-se pela metodologia dedutiva perante uma pesquisa de campo ocorrida em uma escola de ensino profissionalizante do município de Botucatu (SP). Esta pesquisa trouxe novas expectativas e contribuições que vêm desde a ótica de alunos para a modernização do ambiente de ensino e para a criação de oportunidades para a autonomia nos processos de aprendizagem.

Palavras-chave: Novas tecnologias. Formação docente. Autonomia.

Abstract: The main issue related to this article is the adherence to technologies in the classroom, focusing on the study of their good use. There is a theoretical explanation in which it is debated how the same process has been growing over the years, considering other technologies than Smartphones, which are on the rise in Brazil and around the world, being also very present in the classroom. To have a discussion of data, it was chosen the deductive methodology before a field research that took place in a vocational school of Botucatu (São Paulo State - Brazil). This research brought new expectations and contributions that come from the students' perspective to the modernization of the teaching environment and to the creation of opportunities for autonomy in the learning processes.

Key-words: New technologies. Teacher training. Autonomy. 


\section{Introdução}

Logo nos primeiros anos do Ensino Fundamental, um dos grandes inimigos dos professores que vêm ganhando cada vez mais força é o celular. Muitos mestres e mestras se queixam desta ferramenta, como um empecilho ao prosseguimento de suas aulas regulares, bem como uma distração aos alunos que atravessa os muros das instituições de ensino.

Independente do grau escolar, diversos resultados negativos podem ser apresentados por meio do uso desenfreado de celulares em sala de aula. Fraga (2018) relata um experimento realizado em uma instituição de ensino superior em que, com a finalidade de medir os resultados do uso do aparelho, foi mensurada uma tendência ao declínio de metas de estudantes para o desempenho acadêmico, algo que, direta ou indiretamente, também pode influenciar negativamente na obtenção por um posto satisfatório no mercado de trabalho.

Tal levantamento, porém, entra em contraposição à ótica positivista dos celulares como uma representação de democratização da tecnologia manifestada em sala de aula. Campoli (2017) aponta um estudo em que resultados de desempenho são diretamente relacionados ao emprego da tecnologia no ambiente escolar, entre as quais, destacam-se os celulares. O estudo em questão evidencia uma predisposição partida da iniciativa pública e privada de se investir na tecnologia em sala de aula, e o que difere as escolas que auferem os melhores e piores resultados é o incentivo ao uso, partindo dos gestores escolares.

Os estudos retratados acima evidentemente não têm a mesma pretensão, tampouco se apropriam da mesma proposta metodológica, mas podem se complementar se pensado que o primeiro busca compreender os resultados do uso livre da tecnologia e o segundo busca compreender o funcionamento do estudo monitorado e incentivado. Estes, respectivamente, concluem o fator tecnologia como uma distração a ser atenuada, ante um que compreende a tecnologia como um item a ser integrado à busca pelo conhecimento.

Considerada a ascensão tecnológica no ambiente escolar, dentro e fora do que se espera de seu uso, o estudo tem como objetivo analisar os impactos da tecnologia em sala de aula, com foco em celulares smartphones, na ótica de alunos de uma instituição de qualificação profissional em um município localizado no interior doEstado de São Paulo. 


\section{O dilema tecnologia}

Muito se credita a ausência de disciplina e empenho em sala de aula à tecnologia, que oferece opções de entretenimento que aos estudantes se vê muito mais atraente do que uma determinada aula que está fora de suas zonas de interesse. O fato é que mesmo na visão de educadores, a tecnologia é muitas vezes uma ameaça que chega à sala de aula, mas mesmo fora não deixa de ser. Freire (2019) enfatiza que o avanço tecnológico entra em desserviço para com a sociedade enquanto cria novos anseios ao invés de saná-los.

O progresso científico e tecnológico que não responde fundamentalmente aos interesses humanos, às necessidades da nossa existência, perde, para mim, sua significação. A todo avanço tecnológico haveria de corresponder o empenho real de resposta imediata a qualquer desafio que pusesse em risco a alegria de viver dos homens e das mulheres. A um avanço tecnológico que ameaça milhares de mulheres e de homens de perder seu trabalho deveria corresponder outro avanço tecnológico que estivesse a serviço do atendimento das vítimas do processo anterior. Como se vê, esta é uma questão ética e política e não tecnológica. (FREIRE, 2019, p. 127)

Ao trazer a mesma indagação à sala de aula, pode-se ter a tecnologia como bem-vinda ao passo que ela possa atender a determinados objetivos educacionais estabelecidos em programas pedagógicos. Policarpo et al. (2018, p. 42) discorrem um aspecto democrático das vias de disseminação da educação, através da web. Essas vias muitas vezes se apresentam como alternativas únicas de aquisição de conhecimento, sobretudo o conhecimento técnico muitas vezes necessário para que se alcance um determinado posto no ambiente de trabalho, ou uma especialização a quem não conta com uma rotina flexível em termos de horários.

Dentre os fatores positivos do avanço tecnológico, especificamente aos smartphones em sala de aula, Karnal (2012) aponta sua eficácia no processo de aprendizagem enquanto alternativa na busca por uma diversidade de fontes sobre um tema abordado.

A ideia de tecnologia em sala de aula abordada por Karnal (2012) atende ao pressuposto da inversão Lasswelliana no processo comunicativo, atendendo à demanda de educadores progressistas para a formação do pensamento crítico em sala de aula.

Para melhor compreensão, Martino (2017) explica que um processo comunicativo se dá pela relação dialógica entre dois ou mais corpos - sendo eles seres vivos ou não -, sua composição compreende o emissor (responsável) por transmitir uma mensagem, a mensagem (objeto da comunicação) e o receptor (quem recebe a mensagem). 
Entende-se que, em sala de aula, o emissor da mensagem é o educador, a mensagem é o conteúdo de aula e o receptor da mensagem é o aluno.

No Molde Lasswelliano de comunicação, mencionado acima, há uma inversão no processo. Segundo Araújo (2017, p. 123-124), O Molde Lasswelliano, desenvolvido pelo sociólogo, cientista político e teórico da comunicação Harold Lasswell, ao tratar o modelo clássico de comunicação, propõe a inversão do papel do receptor da mensagem, enquanto questiona seu objeto e, consequentemente, se torna também um emissor.

A possibilidade de a tecnologia entrar em voga como uma nova via de busca, há uma oportunidade de tornar a busca de Freire (2019) e Karnal (2012) por uma maior autonomia no processo de ensino e aprendizagem realidade, autonomia esta que permite a quem aprende vivenciar a relação dialógica entre o que se aprende e o motivo para aprendê-lo.

Ao passo que as tecnologias ganham mais força e a internet tem maior protagonismo em espaços onde mesmo o compartilhamento físico de informações não ocorre, há uma clara justificativa para a busca da informação por tal via, muitas vezes compreendida apenas por seu não tradicionalismo. Bittencourt (2017, p. 56-57) reforça a característica ágil das novas ferramentas dos processos de comunicação, bem como sua acessibilidade, cada vez mais notória popularização nos modos de interação social.

A atitude de compartilhar conteúdo não é uma consequência ou algo novo decorrente dessa digitalização da comunicação. Repassar uma informação é algo intrínseco ao processo comunicacional. Querer que uma mensagem chegue a outros, seja a um pequeno grupo ou a uma ampla massa de pessoas, é o objetivo inicial de um processo comunicativo. Sendo então assim há bem mais tempo do que as recentes décadas da sociedade em rede, atos de compartilhar, recomendar e apreciar conteúdos midiáticos vem ganhando uma nova amplitude. Se da escrita nasceu a possibilidade de potencialização do alcance dos conteúdos, com a digitalização de processos pode-se colocar em destaque algo além dessa potencialização. A diversidade de espaços on-line em que as dinâmicas de compartilhamento são cotidianas em muitos casos; assim o são não só pela oferta desse tipo de funcionalidade, mas pela apropriação que os usuários fazem dos mecanismos de funcionamento desses espaços. (BITTENCOURT, 2017, p. 57)

A constatação do uso das tecnologias enquanto via de difusão de informações em tempo real pode não trazer diretamente uma reflexão ao professor e à professora perante suas consequências em sala de aula, mas quando o revés é a aula interrompida por conta do aluno ou da aluna que se vê em estado de entretenimento em redes e mídias sociais, surge uma nova discussão em que este coloca em discussão, de modo equivocado, a qualidade de suas aulas. 
Em um cenário em que as classes C, D e E carecem de acesso à informação e de serviços de comunicação sofisticados, a Internet vem sanar seus anseios. Barreto (2017, p. 73) lembra que o forte investimento na popularização da internet, sobretudo em veículos virtuais de pesquisa como o Google, começa nos Estados Unidos da América e tem por objetivo modernizar os padrões comunicativos vigentes na sociedade, sendo essa medida também compreendida por um avanço no campo científico de forma geral.

Em suma, se a internet passa a ser um incômodo em sala de aula, por oferecer a estudantes condições de acesso à informação e comunicação interpessoal antes impossível, suas discussões não devem necessariamente partir do campo pedagógico, mas sociológico.

Educação, Ensino e Tecnologia dialogam interdisciplinarmente com outras áreas e competências. Meksenas (2014, p. 32) exemplifica a Sociologia como área que depositou diversas contribuições para o desenvolvimento dos estudos da Educação, por pensadores que direta ou indiretamente a tiveram como pauta.

Ainda na busca pelos problemas da influência da tecnologia em sala de aula, há de se propor avaliação e, se necessário, uma autocrítica. Como exposto, o professor e a professora estão absolvidos quanto ao caso do celular em sala de aula, mas ignorar essa realidade pode ser classificado como uma irresponsabilidade. Moran (2013, p. 89-90) enfatiza que há um fator positivo na tecnologia em sala de aula, se aplicada segundo aspectos metodológicos, o problema é que os alunos já estão preparados para isso, mas os professores não.

Perante tais críticas, Lopes et al. (2017, p. 58-59) sugerem que a formação tecnológica de docentes seja efetivamente aproveitada, a fim de que possam lidar com situações em que um celular durante a aula nada mais signifique do que mera dispersão.

Tomando a justificativa sociológica do acesso democrático à informação pelas mais diversas classes sociais, Lopes et al. (2017) apontam uma ideia de luta contra o progresso tecnológico e possivelmente socialmente sustentável, estando também aliada a uma predisposição por parte de docentes a não fugir de uma zona de conforto.

O uso da internet na escola também passou por toda essa dinâmica de discussões, debates, avaliações porque apresentava algumas dificuldades, como a demanda de recursos, de capacitação dos profissionais, entre outros. Naturalmente, com os dispositivos móveis não poderia ser diferente, afinal, tudo que é novo na educação causa certo desconforto porque lidamos com a formação de pessoas, de profissionais, de cidadãos, responsabilidade que nos obriga a questionar, investigar, estudar, analisar e avaliar sempre. (LOPES et al., 2017, p. 63). 
Mais do que uma ferramenta que precisa estar ao lado do(a) educador(a), Silva (2017, p. 132) aponta nos smartphones a afirmação de uma nova formação social, mais democrática no processo de acesso à informação, mas também mais democrática em um processo de horizontalizar tal acessibilidade em termos de faixas etárias, ou seja, assim como o privilégio à informação passou pouco a pouco do domínio total das classes A e B para as classes C, D e E, também o passou do domínio dos mais jovens até os mais idosos.

Jovens e adultos, incluídos no processo de alfabetização, também não podem estar fora do campo de análises dos processos sociais e pedagógicos modernizados de ensino e aprendizagem, ainda mais quando tal modernização visa à autonomia e democratização na aprendizagem e na busca pela informação. Freire (2017, p. 35-36) reitera a necessidade de incluílos na prática pedagógica, a princípio por intermédio de programas de Educação Popular, estando eles acessíveis ao público jovem e adulto, mas nunca eximindo a responsabilidade de educadores e educadoras da consciência social da luta por uma educação democrática e humanista.

Ainda na formação do pedagogo e da pedagoga, que vêm a enfrentar situações de dificuldade com seus alunos e alunas por conta do desenfreado uso de celulares em sala de aula, há de se pontuar que, para todos os públicos, seja em condição econômica ou faixas etárias, o objetivo de quem educa por um viés progressista continua se mantendo o mesmo. Graciani (2014, p. 26) reafirma o caráter emancipatório da educação, ou seja, a busca por formar seres pensantes, que têm no professor e na professora a orientação na própria busca pelo saber, o agente capacitado a orientar sua curiosidade de modo produtivo, bem como sua visão crítica do ambiente social em que estão inseridos.

A ascensão tecnológica no cotidiano de estudantes de todas as faixas etárias e classes sociais responsabiliza igualmente a escola por acompanhar ou não as dinâmicas da sociedade, isso envolve estudar não apenas o papel do docente perante esta situação-problema, mas toda a gestão escolar, desde o baixo até o alto escalão. Silva et al. (2019, p. 187) expressam a necessidade estratégica da escola enquanto facilitadora do bom aproveitamento de novas tecnologias, desde que esta conte com um sistema de gestão de políticas pedagógicas propício para tal abordagem. Tal posição reitera a não responsabilidade exclusiva ao professor e à professora que vem a lidar com esta nova realidade, mas todo um sistema que deve estar em pleno acordo com o desenvolvimento social, no qual a tecnologia também se inclui.

Por fim, Arxer et al. (2018, p. 130) problematizam as relações de dominação e hierarquização de saberes no ambiente escolar, de modo que seja um obstáculo a ser derrubado, a 
fim de que a escola possa se tornar um ambiente de efetiva redução de desigualdades e libertador pelo compartilhamento de saberes e pela construção da autonomia intelectual e da consciência coletiva.

Pensar na escola, portanto, envolve pensar em formação de cidadãos capazes de interpretar o mundo e a realidade social que vivenciam. Para alcançar este objetivo, a escola pode, com sua criatividade, transformar ameaças em potenciais ferramentas estratégicas.

\section{Metodologia da pesquisa}

O método consiste em uma série de regras com a finalidade de resolver determinado problema ou explicar um fato por meio de hipóteses ou teorias que devem ser testadas experimentalmente e podem ser comprovados ou refutados. Se a hipótese for aprovada nos testes, será considerada uma justificativa dos fatos e aceita ou adotada para fins práticos (LAKATOS, 2004, p. 253).

O processo da pesquisa, portanto, é definido pelo estudo dos temas indagados na problematização e na revisão teórica, ou seja, a modernização nos sistemas de gestão escolar, formação docente e as relações entre sociedade e a diversidade nos processos de aprendizagem.

Diversas indagações destacadas no estudo demandaram uma pesquisa de campo para a observação prática das mesmas, o que facilitou o processo de delineamento do estudo das grandes áreas abordadas para as observações mais específicas. Assim, a pesquisa é orientada pelo Método Dedutivo, descrito por Prodanov et al. (2013, p. 27) como uma linha de raciocínio de ordem descendente, que visa explicar o conteúdo de suas premissas, bem como gerar conclusões a partir de duas ou mais hipóteses.

Quanto às afirmações apresentadas desde a problematização ao referencial teórico, a pesquisa de campo visa confrontar esses dados, porém, partindo do ponto de vista do principal receptor no processo de ensino-aprendizagem: o aluno.

Foram entrevistados 65 alunos de faixa etária de 10 a 35 anos de idade em uma escola de ensino profissionalizante no município de Botucatu, interior de São Paulo (SP) entre os dias 16 e 23 de novembro de 2019, sendo optado pela realização em dois sábados por conta das ausências do dia 16 de novembro, sábado que sucedeu o feriado nacional de 15 de novembro.

O questionário busca explicar:

I. Se o(a) aluno(a) tem acesso à internet e onde pode ocorrer. 

pedagógica: uma perspectiva pela ótica de alunos de uma instituição de ensino no município de Botucatu (SP)

II. Tem acesso à internet em sala de aula (no caso de estudantes do ensino fundamental e médio), bem como se a usa ou não.

III. Qual a disciplina escolar ele(a) julga mais adequada para que se agregue à tecnologia em sala de aula.

IV. Se já teve a atenção chamada em sala de aula por conta do uso do celular, e com qual frequência. Parte dos entrevistados não pôde responder,pois não teve celular em sua época de ensino fundamental e médio.

V. Dentre cinco opções, qual melhor representa a opinião do(a) aluno(a) sobre o aproveitamento de celulares enquanto ferramenta pedagógica em sala de aula.

Os autores da pesquisa se valem do direito de realizar a pesquisa sem a necessidade da coleta de informações pessoais dos alunos que se voluntariaram a participar da mesma, à exceção de data de nascimento, idade e sexo. O mesmo ocorreu para com a instituição de ensino que cedeu seu espaço para a realização da pesquisa de campo.

\section{Análise dos dados obtidos}

A instituição que cedeu espaço para a realização da pesquisa tem como foco o atendimento às classes C, D e E. Ainda que realizado no município de Botucatu (SP), dos 65 entrevistados, concentrados na mesma instituição de ensino, algumas parcelas vêm de municípios vizinhos, como São Manuel (SP), Pratânia (SP), Itatinga (SP) e Pardinho (SP).

Referente às faixas etárias dos entrevistados, 16,92\% estão no grupo dos 10 aos 12 anos de idade, 47,69\% estão no grupo dos 13 aos 15 anos, 21,54\% estão no grupo de 16 e 17 anos e 13,85\% dos entrevistados estão no grupo dos 18 anos ou mais, ou seja, oficialmente maiores de idade no Brasil. 52,31\% dos entrevistados são do sexo feminino e 47,69\% dos entrevistados são do sexo masculino.

As respostas das cinco perguntas serão analisadas individualmente e, posteriormente, contextualizadas e analisadas em suas correlações.

\section{Você tem livre acesso à internet?}

A motivação na elaboração desta questão está na busca por saber se os indivíduos das classes econômicas explanadas podem estar sempre conectados à internet através de seus celulares, apontando consigo a possibilidade de responder que esse acesso só pode ocorrer em 
casa, por compartilhamento de rede doméstica, em estabelecimentos com internet liberada ao público ou até mesmo que não acessam a internet.

Majoritariamente, 66,15\% dos entrevistados alegam ter livre acesso à internet, ao passo que 1,54\% não acessam a internet, 10,77\% têm acesso apenas em casa e 21,54\% dizem acessar a internet tanto em casa quanto em estabelecimentos comerciais que oferecem acesso à internet ao seu público. Esta última possibilidade busca, antes de tudo, compreender se gestores aderem à visão de atrair seu público mediante oferta de livre acesso à internet, bem como se a necessidade por seu uso em tais estabelecimentos de alguma forma desperta a consciência e o interesse dos usuários.

02. Você usa internet em sala de aula para:

A maioria dos entrevistados alega que utiliza a internet em sala de aula para tirar dúvidas em relação ao conteúdo dado em aula, totalizando 50,77\% das respostas, enquanto 9,23\% abrem que utilizam internet durante a aula com a única finalidade de conversar com seus amigos, $32,31 \%$ alegam não ter o hábito de utilizar a internet em sala de aula e 7,69\% dizem que a utilizam por outras razões, como pesquisas sobre outros tópicos ou para ter contato com pais e familiares.

Se realizar uma comparação ao conteúdo levantado no embasamento teórico deste artigo, entende-se pela maioria das respostas da pergunta em questão uma predisposição por parte dos alunos à busca pela autonomia de material complementar ao que lhes é ensinado. Entende-se, da mesma maneira, a necessidade de preparação de docentes para que essa busca seja bem orientada, o que se inicia pela aceitação da nova realidade de ascensão de novas tecnologias em salas de aula.

Não se pode, porém, ignorar o posicionamento de 49,23\% dos entrevistados, os quais apontariam dois novos desafios aos docentes e às docentes: orientar a utilização eficiente da internet ao processo de aprendizagem, no caso dos que a utilizam para outros fins e motivar seu uso aos que simplesmente não utilizam, mas poderiam tê-la como aliada e minimizadora de dificuldades intelectuais, bem como ponte ao estímulo à curiosidade.

03. Tendo o acesso à internet disponivel em sala de aula por objetos eletrônicos pessoais (celulares, tablets, laptops, etc.), bá um bom suporte para estudar a disciplina:

A maioria dos entrevistados elegeu a disciplina Inglês, compondo 63,08\% do total dos votos, em seguida Matemática, com 10,77\%, História, com 7,69\%, Ciências, com 4,61\%, Português, com 3,08\%. Havia a disciplina Geografia no questionário, mas não teve votos. 
Há, também, a alternativa "outra", com 10,77\%, sendo esta uma alternativa de livre expressão em que o entrevistado e a entrevistada poderiam expressar uma disciplina ausente ou generalizar a visão com uma pluralidade de disciplinas. $71,42 \%$ dos votos para esta alternativa sugeriram uma generalização para todas as opções, não compreendendo o uso da internet como de extrema relevância para disciplinas mais específicas, ao passo que em 14,29\% dos votos foi sugerido o uso do celular exclusivamente para a disciplina Artes e outros 14,29\% generalizam o uso do celular para todas as disciplinas citadas, excluindo, porém a disciplina matemática, que já havia levado $10,77 \%$ dos votos.

Quanto à justificativa dos votos, pode-se entender que a adesão ao celular para os estudos de Inglês se relaciona ao acesso a mecanismos de tradução, vídeos, áudios, aquisição cultural e chats com nativos do idioma, bem como não nativos dispostos a estudá-lo.

A disciplina Matemática vem como a segunda mais votada, ainda que posteriormente apresente uma contraposição. Sua adesão pode ser compreendida como alternativa a estudos autodidatas em resolução de problemas matemáticos e revisão teórica.

Há de se considerar, porém, interpretações positivas e negativas nas escolhas. Da mesma forma que a internet pode ser muito usada como suporte na aprendizagem de diversas disciplinas, essa ajuda pode mascarar deficiências didáticas na atuação de professores e professoras. É preciso compreender, portanto, que uma formação que prepare profissionais para a docência perante forte ascensão tecnológica não deve ser uma formação que os exima da obrigação de trazer a discussão para a sala de aula, explicações com uma boa didática sobre os principais tópicos abordados, etc.

\section{Algum(a) professor(a) já chamou sua atenção em sala de aula por usar o celular? Se sim, com qual frequência} isso ocorreu?

Esta questão apresenta, com 64,62\% dos votos, uma tendência aos alunos e alunas não terem a atenção chamada por conta do uso de celular em sala de aula. $24,62 \%$ confessa que isso de fato já aconteceu ou acontece, mas com pouca frequência. 6,15\% dos entrevistados abrem que isso ocorre, mas não sabe apontar uma frequência e 4,61\% assumem que ocorre moderadamente.

Sendo uma avaliação pessoal e sem qualquer pressão, pode ser questionado se as tendências apontadas correspondem à realidade, por outro lado, há justificativas para um frequente uso de tecnologias em sala de aula acabar não sendo uma motivação para que profissionais intervenham em seu uso. Algumas dessas observações serão expostas na análise das relações entre as perguntas. 
05. Das op̧̧ões abaixo, qual melhor reproduz, sua opinião sobre o uso de celulares Smartphone em sala de aula?

Destaca-se uma gritante diversidade de opiniões para esta questão. 30,77\% dos entrevistados apresentam uma consciência de que uma abordagem pedagógica com celulares em sala de aula pode dar certo com alguns alunos, mas não com outros. 27,7\% pensam que esta abordagem traria muitas distrações, pois a maioria não compreenderia o celular meramente como uma via de aprendizagem. $20 \%$ dos alunos e alunas entrevistados entendem que o avanço tecnológico justifica o uso dos celulares como via de busca de informações em sala de aula. $15,38 \%$ dos entrevistados veem que tal abordagem pode ocorrer bem desde que seja coordenada por profissionais sérios. Apenas 6,15\% dos entrevistados não têm uma opinião formada sobre o tema.

Algumas das respostas auferem o que o texto considera como um dos desafios de docentes enquanto agentes sujeitos a adquirir uma nova formação, tendo como diretriz a ascensão das novas tecnologias, acesso à informação etc. Distração de alunos e alunas é algo que pode ocorrer não necessariamente pela posse de um celular com acesso à internet, mas por alguma deficiência intelectual, por alguma aula mal elaborada, entre outros motivos.

\section{Análise de correlações das respostas}

Vale ressaltar que 86,15\% dos entrevistados apresentam faixa etária entre 10 e 17 anos, portanto nasceram já no século XXI e passaram pelo ensino fundamental e/ou médio durante a chegada e popularização dos smartphones no Brasil, com isso, suas modalidades de consumo que já vira a tomar conta do ambiente escolar e trazer uma nova roupagem ao comportamento docente no espaço de ensino e aprendizagem.

Dentro da mesma análise, à parte há 13,85\% dos entrevistados que têm 18 anos de idade ou mais, ou seja, dentro do público da classe C, D e E, portanto, menos propensos a terem grandes problemas em sala de aula por conta de celular, o que não significa que fugiam de quaisquer outros atrativos que por ventura os dispersariam das aulas.

É importante também destacar a relação positivista entre os que acreditam que o uso do celular pode trazer algum benefício, ainda que para alguns alunos, os que acreditam na justificativa de seu uso através do avanço tecnológico e os que acreditam nesta abordagem com a coordenação de profissionais sérios - 66,15\%. Estacifra apresenta diferença de 15,38\% superior aos que declaram utilizar a internet em sala de aula a fim de sanar dúvidas em relação ao conteúdo abordado. 
Uma diferença de 15,38\% entre os alunos e alunas que acreditam na positividade da aplicação das novas tecnologias em sala de aula enquanto abordagem pedagógica e os 50,77\% que se valem dessa abordagem indica, ao menos entre os entrevistados, uma possível oportunidade que docentes estão perdendo de tornar o ambiente escolar mais sofisticado e modernizado e orientar seus alunos e alunas a um modelo de aprendizagem cada vez mais autônomo, plural e produtivo.

\section{Considerações finais}

Há uma tendência à predisposição de estudantes ao uso pedagógico eficiente das novas tecnologias em sala de aula, ainda que esses mesmos instrumentos muitas vezes representem fortes fontes de distrações. Tal constatação, partida do cruzamento de dados do embasamento teórico e da pesquisa de campo, não afirma, porém, o fim do uso de apostilas e uso didáticos, mas um atrativo complemento aliado ao que até então se entende por abordagens pedagógicas tradicionais.

Dentre os novos desafios aos docentes, recomenda-se a compreensão do celular em sala de aula não mais como um empecilho no processo de ensino e aprendizagem, mas como um adicional, assim como já foi explanado, mas, primeiramente, uma análise e autocrítica quanto à reação do docente perante este cenário. Entende-se por isso uma busca a este novo universo enquanto oportunidade, ou seja, saber até que ponto um celular em aula pode ser aproveitado enquanto ferramenta pedagógica.

De maneira geral, a partir da pesquisa, sugere-se às escolas um mapeamento dos processos pedagógicos, uma avaliação do que já ocorre em termos de adesão às tecnologias em sala de aula e fora, ou seja, laboratórios democráticos de informática, a fim de propiciar boa usabilidade a todo o aluno e à aluna que têm uma curiosidade que vá para além das paredes da sala de aula e só necessitam um espaço propício à busca autônoma por informações e pela constituição de seu conhecimento.

\section{Referências}

ARAÚJO, C.A. A pesquisa norte-americana. In: HOHLFELD, A.; MARTINO, L. C.; FRANÇA, V. V. Teorias da comunicaşão: Conceitos, escolas e tendências. Petrópolis: Vozes, 2017, 15. ed., p. 119-130.

ARXER, E. A.; ZANON, D. A. V.; BIZELLI, J. L. Contribuições do processo reflexivo parao entendimento da prática docente.Dialogia, São Paulo, n. 28, p. 121-132, jan./abr. 2018. 


\section{Dialogia}

GOMES, Mike Ceriani de Oliveira; PIZA, Mariana Wagner de Toledo. A tecnologia em sala de aula como ferramenta pedagógica: uma perspectiva pela ótica de alunos de uma instituição de ensino no município de Botucatu (SP)

BARRETO, G. Cidadania e internet: entre a representação midiática e a representatividade política. Curitiba: Appris, 2017.

BITTENCOURT, M. C. A. Convergência midiática e redes digitais: modelo de análise para pesquisas em comunicação. Curitiba: Appris, 2017.

CAMPOLI, C. 52\% das instituições de educação básica usam celular em atividades escolares, aponta estudo da Cetic:De 2015 para 2016, número de professores que usam a internet do celular em atividades com os alunos cresceu em 10\%. 2017. Disponível em:

https://g1.globo.com/educacao/noticia/52-das-instituicoes-de-educacao-basica-usam-celularem-atividades-escolares-aponta-estudo-da-cetic.ghtml.Acesso em: em 17 nov. 2019.

FRAGA, É.Uso de celular em sala de aula dobra efeito negativo nas notas, aponta estudo:Pesquisa da FGV mediu impacto da utilização em excesso dos aparelhos. 2018. Disponível em:

https://www1.folha.uol.com.br/educacao/2018/09/uso-de-celular-em-sala-de-aula-dobra-efeitonegativo-nas-notas-aponta-estudo.shtml. Acesso em: 17 nov. 2019.

FREIRE, P. Pedagogia da autonomia: saberes necessários à prática educativa. 59. ed. Rio de Janeiro/São Paulo: Paz e Terra, 2019.

FREIRE, P. Política e educação.3. ed. Rio de Janeiro/São Paulo: Paz e Terra, 2017.

GRACIANI, M. S.S. Pedagogia Social.São Paulo: Cortez, 2014.

KARNAL, L.Conversas com um jovem professor.São Paulo:Contexto, 2012.

LAKATOS, E.M. Metodologia cientifica. 4. ed. São Paulo: Atlas, 2004.

LOPES, P. A.; PIMENTA, C. C. C. O uso do celular em sala de aula como ferramenta pedagógica: Benefícios e desafios. Cadernos de Estudos e Pesquisa na Educaşão,v. 3, n. 1, p. 52-66, 2017.

MARTINO, L.C. de qual comunicação estamos falando? In: HOHLFELD, A.; MARTINO, L. C.; FRANÇA, V. V. Teorias da comunicação: Conceitos, escolas e tendências. Petrópolis: Vozes, 2017, 15. ed., p. 11-25.

MEKSENAS, P. Sociologia da educação: Introdução ao estudo da escola no processo de transformação social. 17. ed. São Paulo: Edições Loyola, 2014.

MORAN, J. A Educaşão que desejamos: novos desafios e como chegar lá. 5.ed. Campinas: Papirus, 2013.

POLICARPO, C.; SANTAELLA, L. A estética do conhecimento nas redes digitais. Dialogia, São Paulo, n. 28, p. 29-45, jan./abr. 2018.

PRODANOV, C. C.; FREITAS, E.C.Metodologia do trabalho cientifico: métodos e técnicas da pesquisa e do trabalho acadêmico. 2. ed. Novo Hamburgo: Freevale, 2013.

SILVA, G.; VIANA, M. A.P. As tecnologias na educação: o papel da equipe gestora nas práticas pedagógicas. Dialogia, São Paulo, n. 32, p. 183-198, maio/ago. 2019. 


\section{Dialogia}

GOMES, Mike Ceriani de Oliveira; PIZA, Mariana Wagner de Toledo. A tecnologia em sala de aula como ferramenta pedagógica: uma perspectiva pela ótica de alunos de uma instituição de ensino no município de Botucatu (SP)

SILVA, M.C. USO DO SMARTPHONE COMO RECURSO DIDÁTICO PARA O ENSINO DA LÍNGUA PORTUGUESA. Revista de Estudos Acadêmicos de Letras,v. 10, n. 01, p. 124-133, 2017.

Recebido em: 14 fev. 2020 / Aprovado em: 19 mar. 2020

Cite como (ABNT NBR 6023:2018)

GOMES, Mike Ceriani de Oliveira; PIZA, Mariana Wagner de Toledo. A tecnologia em sala de aula como ferramenta pedagógica: uma perspectiva pela ótica de alunos de uma instituição de ensino no município de Botucatu (SP). Dialogia, São Paulo, n. 34, p. 323-336, jan./abr. 2020. Disponível em: https://doi.org/10.5585/Dialogia.N34.16608. 